\title{
The Review of the Buddhism History and Culture in Kashgar
}

\author{
Wenyi Xia \\ Organization Department \\ Kashgar University \\ Kashgar City, Sinkiang, China 844008
}

\begin{abstract}
The influence of Islam on Kashgar is farreaching. The history of Buddhism culture tends to be ignored. This article introduces the introduction, prosperity, reasons of Buddhism's declining and the existing Buddhism relics to describe the historical development process of Buddhism in Shule (now Kashgar) for rising the interest and attention of researchers on it.
\end{abstract}

Keywords-Kashgar; Shule; Buddhism; culture

\section{INTRODUCTION}

As we all know, Kashgar (also known as Mahmud Khashigari, and Shule in the past) has been deeply affected by religious culture. Especially, Islam exerts a profound influence on the region with its long history over a thousand years since being introduced here in the mid-tenth century. However, Buddhism is often neglected when it comes to the religious history of Kashgar, but the fact is that the predecessor of Kashgar-Shule is one of the "four major Buddhist culture centers of western regions" with the history of near a thousand years and colorful ancient culture of Buddhism. The other three regions include the Kingdom of Khotan (now Khotan), Qiuci (now Kuqa) and Gaochang (now Turpan). Among western regions, Buddhism was the most long-lasting religion in local history, which has most followers, deepest social influence as well as the most abundant cultural relics, some of which remain to today, leaving a wonderful page in local religious culture history. By analyzing the introduction, prosperity, decline and causes, along with the existing historical cultural relics and remains in Kashgar, this paper reviews the development course of Buddhism in Shule (now Kashgar) so as to start the discussion and to enrich the multicultural research of Kashgar.

\section{BUDDHISM HISTORY IN KASHGAR}

\section{A. Introduction of Buddhism}

From the 6th century $\mathrm{BC}$ to the 5th century BC, Sakyamuni founded Buddhism and preached in the middle and upper reaches of the Ganges River of India, and over a period of hundreds of years, Buddhism has been rapidly introduced from Gandhara (now the regions of Peshawar of Pakistan and Indus) and Kasmira (now Kashmir) to the Central Asia then to the south regions of Har goolun Range and Pamirs. According to research, in the 1st century BC (About $73 \mathrm{BC}$ ), an eminent monk from Kasmira named Vairocana had spread Buddhism to the Kingdom of Khotan (now Khotan) and then to Shule (now Kashgar, the same below). This was more than one century before the introduction of Buddhism to Chinese mainland in the Mingdi administration of the Eastern Han Dynasty (58-75 DC).

It is commonly thought that there are two routes, along which Buddhism was introduced to Shule. One started from India then bypassing Rouzhi and moving eastward after through Tielieketi pass; the other began from northwest India to the Wakhan Corridor (now Afghanistan) and then across Pamir and finally to Shule via Khunjerab pass (Wang Shiyang. The History and Culture of Kashgar. 2009: 62). In fact, Buddhism was not widely accepted in the very first beginning when introduced into Shule. Besides, limited by language and no written records of Buddhist texts, the missionary work was carried out mainly by individual monk walking among people preaching orally, so Buddhists had to memorize the doctrine by heart. In addition, they did not have permanent adherents let along fixed preaching site and therefore, the Buddhism there had little influence on the local.

\section{B. Rising, Spreading and Declining of Buddhism in Shule (Now Kashgar)}

Due to the enthusiasm of the king of Shule Chenpan and the need of ruling, Buddhism was rising and spreading in Shule at the beginning of the 2 nd century. Before the Eastern Han Dynasty, Shule was dominated by primitive religions such as Shamanism and nature worship that no longer adapted to new social relations of production. Moreover, Buddhism is more in favor of the government of feudal rulers by means of the concepts of hierarchy, polytheism and the supreme god together with other doctrines. As a result, under the leading and guidance of the ruler, Shule became the first area of western regions to regard Buddhism as national religion. With the top-down implementation, Buddhism firstly prevailed in royal court and the noble while it was coexisted with nature worship such as Shamanism in folk. Buddhism was not prosperous until the Southern and Northern Dynasties (from the end of the 2nd century to the end of the 6th century), and began to decline in the 8th century after reaching its peak in the end of the 7th century. In 960 DC, Karakhanid Empire of Kashgar declared Islam as 
the national religion, when Buddhism withdrew from the stage of religious history of Shule.

\section{Reasons for the Decline from Prosperity of Buddhism in Shule (Now Kashgar)}

Firstly, Hinayana had been playing a leading role in Shule throughout its development course in this region from the introduction to the rising then to its declining, but weak foundation in doctrines and principles gave Islam a good opportunity to spread westward. Hinayana reveres Sakyamuni as the supreme hierarch who advocates ascesis so as to obtain self-emancipation (that is "self-interestedness"), aiming to achieve the supreme goal of "dispelling all the worries and sorrows". Besides, bordering Karakhanid Empire, the Buddhist town Shule definitely bore the brunt of the expansion of the Karakhanid Empire in the mid-tenth century, causing the conflict between Buddhism with Islam. Moreover, with the prosperity of Buddhism, there were numerous Buddhists holding plenty of ceremonies that wasted much of social wealth, adversely affecting the normal development of the economy. In 644 DC, when monk Xuanzang passed through Shule in his return trip, he commented: "people there adhere to Buddhist doctrine piously and take activity in creating interests. Hundreds of temples are built accommodating more than ten thousand Buddhists" (Records of the Western Regions of the Great Tang. Page 154). In 690, Empress Wu Zetian issued Dayunjing throughout the country and ordered to build "Dayun temple". It took more than ten years for the area command of Shule to complete the Dayun Buddhist temple that was well known in western regions and has been highly spoken of until the mid-eighth century. However, it is clear that large group of monks occupied a great amount of social wealth to hold Buddhist ceremonies and build Buddhist sites, affecting adversely the development of local economy and military power. As a result, Buddhism power had no ability to fight against Islam in long term when being intrude dupon by Islam, leading to the inevitable decline of the Buddhism. In addition, after long-term wars and conflicts in Five Dynasties and Ten Kingdoms period, the newly founded Northern Song Dynasty was too busy dealing with the northern border security to pay attention to the western regions in addition to its relatively weak power without the capacity to control the western regions directly comparing with Tang Dynasty. In conclusion, without the protection of the central power of Northern Song Dynasty, traditional Buddhism power began to decline and withdrew from the historical stage in the end.

\section{BUdDHIST CULTURE IN KASHGAR}

\section{A. The Representative Work of Gandhara Culture-“Mohr Pagoda" \\ "Mohr", also translated as "Moredun" "Moratimo", means "flue" or "chimney" in Uyghur language, and the name came from a place named Mohr where two turrets were considered as ancient beacon towers by the locals. Actually, it is a famous Buddhist temple remain nearby the ancient Shule Kingdom in the western regions of China, now}

situated in a sand dune of the middle section of Matago mountains, over twenty kilometers to the northeast of Kashgar city. Besides, the Mohr Pagoda faces south, several kilometers to the Hannuoyi ancient city in the other bank of the ancient channel of the Qiakemake River. It was completed in the middle and late period of Tang Dynasty and Stein had depicted it together with other Buddhist sites nearby and their topography. Besides, pottery shreds, pieces of ancient currency, remains of a grape vine and the deserted Karez were excavated around the zone.

Gandhara art is the Buddhism art centering on the ancient Gandhara region that is now situated in Peshawar of Pakistan and the adjacent western Afghanistan. For several centuries before common era, this region successively belonged to the possession of Persian Empire, the Greek empire of Alexandria and Hellenistic Bactria empire (Balkh); in the first half of the 1st century, it became a region of Kushan Empire of Yuezhi and based in Gongloushacheng (now Peshawar), from which Buddhism was introduced to Shule. (Wang Shiyang, 2009, 612-613)

Mohr Pagoda site is a typical Gandhara building. Most of domestic Buddhist statues are the reproduction or transformation of Gandhara arts. Moreover, Buddhists in ancient Shule kingdom had been playing the role of inheritor of the Gandhara arts, and this evidence of the fact can still be tracked. In general, two of the shapes of the pagoda were never found in central China, neither in ancient western regions. It is almost the counterpart of the Buddhist architecture art of Gandhara in Shule. Over 600 years from the end of 2 nd century to the end of the 8th century, Buddhist temples of all scales had been established constantly. Whether Mohr Pagoda was located in Dayun temple or in Longxin temple of Shule has not been figured out, but in accordance with Stein's description of the relics of the temple group around 30-kilometer radius of ancient Hannuoyi city, it is likely to be one of them. Mohr Pagoda as the last Buddhist remains in Shule, its historical mission ended with the official introduction of Islam to Kashgar.

\section{B. The Brand of Hinayana-"Three Immortals Cave"}

It is an important symbol to excavate caves and draw frescos of the early Buddhism. After the 1st century AD, grottos with Buddhist paintings on the wall appeared with the advent of Buddhist statues. These frescos on grottos not only propagate Buddhist ideology through artistic form but also provide sites for Buddhists for seclusion and penance. Therefore, in the early days, Buddhism activities of Hinayana were often held in these caves or nearby. Influenced by the Buddhists of Mahayana who built large temples to hold Buddhism activities, Buddhists of Hinayana also started to establish temples and pagodas, but they never abandoned their tradition of digging grottos with frescos on the wall, only these caves were used for Buddhist texts storing and penance. With the prosperity of Buddhism in Kashgar kingdom, Buddhists of Hinayana dug caves with Buddhist paintings showing the tradition of primitive Buddhism such as the "Three Immortals Cave" that remains to this day. 
The "Three Immortals Cave" is situated in the halfway up the wall right to the Boshikeranmu river around 10 kilometers to the northern Kashgar suburb, and such location makes it difficult to get into the cave bare-handed in addition to the bare cliff under thousands of years' water scouring, but it can be preserved for that reason. Suerde and the grand minister consultant of Kashgar Hening had inspected the "Three Immortals Cave" but did not unfold its mystery. Until September 1979, a staff member of the museum of the municipality came to inspect here accompanied by personnel members of Kashgar, when the mystery was finally uncovered. It was found out that the "Three Immortals Cave" was dug in the Eastern Han Dynasty and is the oldest cave remained in the western regions of China, having great historical value. It was also verified that Shule is one of the regions that Buddhism was firstly introduced to. Moreover, the maturity of the Buddhist statues and murals art inside the cave is the sign of the consolidation of Buddhism in Shule at that time. It is also can be derived by time that the cave was dug around the late period of Chenpan administration in Shule and is likely to be the only Buddhist remain after his practice of Buddhism.

\section{CONCLUSION}

As we all know, profoundly influenced by Islamic culture, Kashgar is also widely known as "the holy land at Central Asia", and consequently, researchers at home and abroad are always focusing on this in the research of religion. In fact, the ancient Shule kingdom, as the predecessor of Kashgar, played an important role on the Buddhism history of the western regions. Additionally, as one of the four Buddhist cultural centers, although Shule is incomparable with the other three regions when it comes to the influence of Buddhist culture, it is still one crucial link in terms of the history and culture of Kashgar and even the western region. Owing to few excavated Buddhist remains and existing literature, in addition to the fact that Shule (now Kashgar) was the first region that Islam was introduced to, the local Buddhist culture was mostly destroyed. However, its position in the Buddhism history of western regions should not be ignored.

\section{REFERENCES}

[1] (Tang Dynasty) Xuanzang (writer), Zhang xun (annotator). Records of the Western Regions of the Great Tang. Shanghai,Shanghai People's Publishing House, 1977.

[2] Wang Shiyang. History and Culture of Kashgar. Sinkiang People's Publishing House, 2009, (62: 612-613)

[3] Dictionary of Chinese Spots. Shanghai, Shanghai Lexicographical Publishing House, 2003 (1107) 